\title{
Neurobehaviour of school age children born to diabetic mothers
}

\author{
A Ornoy, N Ratzon, C Greenbaum, E Peretz, D Soriano, M Dulitzky
}

Laboratory of Teratology, Department of Anatomy and Cel Biology,

Hebrew University, Jerusalem, Israel

A Ornoy

N Ratzon

Department of Psychology

C Greenbaum

School of Public Health

E Peretz

Sheba Medical Center, Tel Aviv University, Israel

D Soriano

M Dulitzky

Correspondence to: Dr Asher Ornoy, The Hebrew University Hadassah Medical School Jerusalem

PO Box 12272, Jerusalem 91120 , Israel.

Accepted 11 March 1998

\begin{abstract}
Aim-To study the neurobehavioural effects that diabetes during pregnancy might have on children by school age.

Methods-The neurobehavioural function of 57 school age children born to 48 , well controlled diabetic mothers was compared with 57 control children matched for age, birth order, and parental socioeconomic status, using several cognitive, behavioural, sensory and motor neurological tests.

Results-The IQ scores of the index group children were similar to those of control children $(117.7 \pm 13.4$ vs $118.5 \pm 10.1)$. There were no differences between the groups in various sensory motor functions. However, the index group children performed less well than the controls on indices of fine and gross motor functions, as observed on the Bruininks-Oseretzky test of motor proficiency. The scores of children born to diabetic mothers were higher than controls on the Touwen and Prechtl neurological examination. They also performed worse in the Pollack tapper test which is designed to detect minor neurological deficits, inattention, and hyperactivity. The index children had higher scores on the Conners abbreviated parent-teacher questionnaire which measures hyperactivity and inattention. There was a negative correlation between the performance of the index group children on various neurodevelopmental and behavioural tests and the severity of hyperglycaemia, as assessed by blood glycosylated haemoglobin and acetonuria.

Conclusions-Diabetes during pregnancy adversely affects some fine neurological functions in children at school age, but not their cognitive scores. These effects are not correlated with the degree of glycaemic control.

(Arch Dis Child Fetal Neonatal Ed 1998;79:F94-F99)
\end{abstract}

Keywords: diabetes; pregnancy; school age children; neurological functions

Diabetes during pregnancy is associated with an increased rate of spontaneous abortions, intrauterine death, and congenital anomalies. ${ }^{1-8}$ This is directly related to the severity of the disease, and may also be related to glycosylated haemoglobin $\left(\mathrm{HbA}_{1 \mathrm{c}}\right)$ blood concen trations. ${ }^{4-11}$ Over the past 10 to 15 years, there seems to have been a significant reduction in the prevalence of congenital anomalies among the children of diabetic mothers. This is directly related to the improvement in glycaemic control during early pregnancy, and the rate of congenital anomalies has significantly reduced in well treated diabetic pregnant women. $^{36}$

Gestational diabetes, which develops exclusively in the second half of pregnancy, can cause major metabolic dysfunction, which may induce an increase in the rate of developmental disorders in the children. We found an increased rate of minor neurological dysfunction in a group of 32 children born to mothers with gestational diabetes, including some fine and gross motor deficits, compared with a group of control children. ${ }^{12}$ This is not entirely unexpected as the major development of the cerebral cortex occurs during the second half of pregnancy. ${ }^{12} 13$

More than 27 years ago, Shulte $e t a l^{14}$ studied the neurological development of newborn infants born to diabetic mothers, compared with that in control newborn infants. They found longer rapid eye movement (REM) sleep in newborn infants of diabetic mothers. Stehbens et $a l^{15}$ examined children born to diabetic mothers at 1,3 , and 5 years of age. The small for gestational age children born to diabetic mothers, or children born to diabetic mothers who started follow up late in pregnancy, had lower cognitive scores and verbal performance compared with controls. ${ }^{16}{ }^{17}$ Other investigators have not found any differences in cognitive scores. ${ }^{18-22}$

Children born to diabetic mothers may sustain minor neurological damage which does not necessarily affect their scores in IQ tests. Alternatively, neurological damage may be present but may express itself in neuropsychological abilities at ages later than those studied before. Children born after high risk pregnancies tend to have developmental delay, learning difficulties at school, and a high rate of attention and hyperactivity disorders (ADHD), although predictors of individual outcome are difficult to determine. ${ }^{23}$ The Diagnostic and Statistical Manual-IV (DSM-IV) ${ }^{24}$ indicates that ADHD is associated with other behavioural problems. Intellectual ability in children with ADHD is usually within the normal range. ${ }^{2324}$ As the developmental studies performed on children born to diabetic mothers have usually been carried out at preschool age, the issue of whether diabetes may have some effect on the prevalence of ADHD has rarely been discussed.

The purpose of this study was to assess the neurobehaviour of early school age children born to diabetic mothers and to compare it with pair matched controls, using several cognitive, sensory, motor, behavioural and 
neurological tests. We also intended to correlate the neurological function of these children with the degree of metabolic dysfunction observed in the diabetic mothers.

\section{Methods}

The sample consisted of 57 children (49\% girls), born to 48 type I and type II diabetic mothers and 57 control children ( $44 \%$ girls) born to 57 non-diabetic healthy mothers, pair matched on age, socioeconomic status (based on parental education and occupation), ${ }^{26}$ gestational age, birth order and family size. In Israel, each pregnant woman is routinely screened for gestational diabetes. None of the control mothers had gestational diabetes. All children were born between $1982-7$ at the Sheba Medical Center, Tel Hashomer, near Tel Aviv, where the diabetic mothers were also followed up and their diabetes managed, with the aim of achieving optimal glycaemic control. The average age of the children in the index group was $8.09 \pm 1.77$ years, ranging from 5.2 12.1 years ( 16 children $(28 \%) 5-6$ years of age; 22 children (38\%) 7-8 years; and 19 children (34\%) 9-12 years); and in the control children it was $8.29 \pm 1.78$ years, ranging between 5.5 12.2 years ( $5-6$ years $(33 \%) ; 7-8$ years $(33 \%)$; and $9-12$ years $(33 \%))$. All children studied in normal schools. Parental education (as assessed from the personal questionnaires) was similar in the index and control groups. Average maternal education in the index group was 13.2 years and in the controls it was 13.1 years. Average paternal education was 13 years in both groups. When calculated for both parents, $18 \%$ had eight to 11 years of education; $51 \%$ had $12-14$ years, and $31 \%$ had over 15 years of education.

All mothers of the children in the index group were treated in the high risk pregnancy clinic at Sheba Medical Center. Initially, there were 62 diabetic pregnant women treated during that period. Of these, eight women could not be located, five lived too far away from the site of examination and therefore could not participate. One child was born with multiple anomalies and mental retardation, and was excluded from the study. The remaining 48 women had 57 children of appropriate age for examination. There were 29 boys $(50.9 \%)$ and $28(49.1 \%)$ girls.

To control for the fact that nine of the 48 diabetic women had two children who participated in the study, we first compared the results of 48 index children with those of 48 pair matched control children. Matching was performed once with the younger of the siblings and once with the elder sibling. The differences between index and control groups found between 48 children were unchanged when all 57 children of each group were compared. We therefore compared all 57 children from each of the groups for all tests.

We constructed our control sample by searching the birth record at the Sheba Medical Center for 1982-7, and contacting parents by telephone. We found 67 children who lived at distances up to $100 \mathrm{~km}$ from the hospital, and who were suitable to serve as pair matched controls. Of these, 32 parents $(47 \%)$, mostly from areas far from the hospital, found it too difficult to participate and we examined the remaining 35 children from areas that were closer. To complete the control group, we also included 22 children from a nearby school. These 22 and the other 35 children were similar on background characteristics and on the outcome variables described below. The children were matched by age and school placement (all studying in normal schools) as well as by gestational age, birth order, and parental education. There were 32 boys $(56.1 \%)$ and 25 $(43.9 \%)$ girls in the control group. The study was carried out for one year (1995).

We compared the neurobehaviour of early school age children born at more than 34 weeks of gestation to diabetic mothers with agematched control children according to several criteria. The following tests were administered to each participating child:

A complete physical examination.

The Touwen-Prechtl neurological examination for minor nervous dysfunction. ${ }^{27}$ Abnormal neurological findings on this test were scored, and a total score of 10 or more was considered abnormal-that is, pointing to some neurological impairment. ${ }^{25}$

The Pollack tapper test. ${ }^{28}$ This test is designed to assess attention deficits. The child is asked to repeat a specific sequence of light blinks and auditory taps presented by the tester. The number, sequence, and duration of these stimuli is adapted to the child's age. Children with attention deficit tend to obtain lower scores than children with normal attention span. The test yields a separate score indicating success in repeating visual and auditory stimuli as well as a total score. The higher the score, the better the child's attention to rhythmic stimuli. $^{28}$

Evaluation of the cognitive score using the Wechsler Intelligence Scales for Children, Revised (WISC-R, 1974).

Bender Visual Gestalt test ${ }^{29}{ }^{30}$ for the evaluation of hand-eye coordination.

Bruininks-Oseretsky Motor Development test. ${ }^{31}$ This test examines fine and gross motor development of children aged 4.5-14.5 years.

Southern California Integration Test ${ }^{32}$ for the evaluation of children's sensory functioning. This test includes three subtests: manual form perception (MFP), finger identification ( $\mathrm{FI}$ ), and localisation of tactile stimuli (LTS). The test was carried out by an occupational therapist.

The Conners Abbreviated Parent-Teacher Questionnaire ${ }^{34}$ for the study of hyperactivity and attention problems was administered to the parents. The lower the score is, the less hyperactivity and attention problems the child has.

A developmental paediatrician, a developmental psychologist, and an occupational therapist administered the tests. In all cases the tester was unaware of the mother's diabetic status.

The medical records of 53 out of 57 pregnancies of women in the index group were available for analysis. The clinical details 
Table 1 Comparison of physical evaluations between control children and children born to diabetic mothers

\begin{tabular}{lccccc}
\hline & $\begin{array}{l}\text { Control } \\
\text { Mean (SE) }\end{array}$ & $\begin{array}{l}\text { Diabetic mothers } \\
\text { Mean (SE) }\end{array}$ & $\begin{array}{l}\text { Mean } \\
\text { difference }\end{array}$ & $\begin{array}{l}\text { SE of mean } \\
\text { difference }\end{array}$ & $p$ Valuet \\
\hline Birthweight $(\mathrm{g})$ & $3381(75.3)$ & $3528(84.5)$ & 147 & 2.8 & 0.07 \\
Head circumference percentile & $48.4(3.2)$ & $46.8(3.2)$ & -2.0 & 4.4 & 0.79 \\
Height percentile & $43.8(4.0)$ & $45.0(4.3)$ & 1.8 & 5.4 & 0.89 \\
Weight percentile & $41.8(4.1)^{\star}$ & $56.9(4.4)$ & 18.1 & 5.8 & 0.02 \\
\hline
\end{tabular}

* Significantly lower than diabetic mothers; † paired $t$ test.

included the time of onset of diabetes, the time of pregnancy when tight control of diabetes started, the stage of diabetes for each woman (White's stages), and the presence of hypertension, retinopathy, nephropathy, or neuropathy of diabetes. The laboratory examinations performed included pre- and postprandial glucose blood concentrations up to six times/day by the pregnant women using a glucometer.

For each woman we calculated: average blood glucose concentrations and counted the number of cases of hypoglycaemia $(<60 \mathrm{mg} / \mathrm{dl})$ or hyperglycaemia ( blood glucose concentrations of $160-199$ or above $200 \mathrm{mg} / \mathrm{dl}$ ) in relation to the week of pregnancy; number of times urinary acetone was found on routine screening, done several times each week; presence of abnormal liver function tests; duration and complications of diabetes according to White's classification.

Reports of average percentage of glycosylated haemoglobin $\left(\mathrm{HbA}_{1 \mathrm{c}}\right)$ was available only for 19 pregnancies. To check on possible information bias we compared the results on demographic and metabolic variables for these women with those of the other women in the index group using the Mann-Whitney $U$ test and found no difference between the groups. All these variables were correlated with the results of the neurobehavioural assessments of the children.

We compared index and control groups using paired $t$ tests for each result (cognitive and motor scores). For comparison of the groups on the Touwen and Prechtl neurological examinations, we used the Wilcoxon matched pair signed rank test.

Pearson correlations were calculated between the scores on the neurodevelopmental tests of the children and the metabolic findings of the diabetic mothers. ${ }^{35}$ As the correlations in each trimester were similar, we calculated the correlations for the entire period of pregnancy.

\section{Results}

Three children of diabetic mothers were born with congenital anomalies: (one child, already mentioned, was born with mental retardation and was not included in the study). Two children were born with congenital anomalies but had normal intelligence (IQ>90). One of these, a boy, had severe bilateral club feet and bilateral hip dislocation, and the other, a girl, had unilateral aplasia of the right arm. Sixteen index group children $(28.6 \%)$ were delivered by cesarean section as opposed to five $(8.8 \%)$ in the controls $(\chi 2, p=0.06)$. Ten $(17 \%)$ children in the index group had neonatal hypoglycaemia and none in the control group $(\chi 2$, $\mathrm{p}=0.004)$.

Table 1 shows birthweight and selected results of the physical examination. The average birthweight of the index group children was $3528 \mathrm{~g}$ (range $2220-4820 \mathrm{~g}$ ) and of the controls $3381 \mathrm{~g}$ (range 1950-4410 g). The differences between the groups were not statistically significant. Children born to diabetic mothers were heavier than controls in body weight (higher percentiles) at examination. There were no differences at examination in head circumference and height.

Table 2 shows the results of the WISC-R and Bender tests for the index and control children. No differences were found between the index and control groups. Results of the neurological and the motor assessments of the children are given in table 3 . Children born to diabetic mothers had significantly lower scores on the Bruininks-Oseretsky fine and gross motor scores than the controls $(\mathrm{p}=0.03)$.

Table 2 Comparison of cognitive scores on WISC-R and Bender Gestalt test of control children and those born to diabetic mothers

\begin{tabular}{lccccc}
\hline Test & $\begin{array}{l}\text { Control } \\
\text { Mean (SE) }\end{array}$ & $\begin{array}{l}\text { Diabetic mothers } \\
\text { Mean (SE) }\end{array}$ & $\begin{array}{l}\text { Mean } \\
\text { difference }\end{array}$ & $\begin{array}{l}\text { SE of mean } \\
\text { difference }\end{array}$ & $p$ Values \\
\hline IQ & $118.5(1.3)$ & $117.7(1.7)$ & -1.0 & 2.0 & 0.60 \\
$\quad$ Verbal & $114.4(1.6)$ & $112.4(1.7)$ & -2.0 & 2.2 & 0.37 \\
$\quad$ Performance & $119.7(1.5)$ & $120.4(1.9)$ & 0.6 & 2.3 & 0.78 \\
Bender (\%) & $48.6(3.7)$ & $48.0(4.0)$ & -0.6 & 5.2 & 0.90 \\
\hline
\end{tabular}

Table 3 Comparison of motor development (Bruininks-Oseretzky) and of neurological and behavioural evaluation (Touwen Ë Prechtl, Pollack and Conners) in control children and those born to diabetic mothers

\begin{tabular}{|c|c|c|c|c|c|c|c|}
\hline \multirow{2}{*}{$\frac{\text { Test }}{\text { Bruininks total }}$} & \multicolumn{2}{|c|}{$\begin{array}{l}\text { Control } \\
\text { Mean (SE) }\end{array}$} & \multicolumn{2}{|c|}{$\begin{array}{l}\text { Diabetic mothers } \\
\text { Mean (SE) }\end{array}$} & \multirow{2}{*}{$\begin{array}{l}\text { Mean } \\
\text { difference }\end{array}$} & \multirow{2}{*}{$\begin{array}{l}\begin{array}{l}\text { SE of mean } \\
\text { difference }\end{array} \\
3.2\end{array}$} & \multirow{2}{*}{$\frac{p \text { Value }}{0.008}$} \\
\hline & $138.2 \dagger$ & $(3.7)^{\star}$ & 129.2 & (3.9) & & & \\
\hline Bruininks gross motor & 60.8 & $(1.7)^{\star}$ & 57.2 & (1.7) & -3.6 & 1.6 & 0.03 \\
\hline Bruininks fine motor & 62.5 & $(1.7)^{\star}$ & 58.0 & (1.9) & -4.5 & 1.7 & 0.01 \\
\hline Touwen and Prechtl (No of failure signs) & $4.00 \ddagger$ & & 8.45 & & - & - & 0.01 \\
\hline Pollack & 28.9 & $(0.7)^{\star}$ & 24.3 & (1.6) & -4.6 & 1.7 & 0.008 \\
\hline Conners & 7.7 & $(0.5)$ & 9.1 & $(0.8)$ & 1.2 & 1.0 & 0.24 \\
\hline
\end{tabular}

$\star$ Significantly higher than index group; $†$ Mean $(\mathrm{SD}) ; \ddagger$ Significantly lower than index group, Wilcoxon matched pair; $₫$ Paired $t$ test. 
Table 4 Correlation between indices of maternal glycaemic control and the results of neurodevelopmental assessment

\begin{tabular}{|c|c|c|c|c|}
\hline Neurological test & $\begin{array}{l}\text { Maternal blood } \\
\text { glucose }(n=47)\end{array}$ & $\begin{array}{l}\text { Glycosylated } \\
\text { haemoglobin }(n=19)\end{array}$ & $\begin{array}{l}\text { Acetonuria } \\
(n=46)\end{array}$ & $\begin{array}{l}\text { Glycaemic control: } \\
\text { White's classified }(n=53)\end{array}$ \\
\hline Touwen and Prechtl & -0.07 & 0.03 & 0.15 & 0.00 \\
\hline IQ-general & $0.27^{\star}$ & -0.07 & 0.01 & -0.03 \\
\hline Bender & $0.32^{\star}$ & $-0.50^{\star}$ & 0.06 & 0.00 \\
\hline Bruininks, general motor & 0.10 & $-0.41^{\star}$ & $-0.31^{\star}$ & -0.08 \\
\hline Bruininks, gross motor & 0.03 & $0.33^{\star}$ & $-0.27^{\star}$ & 0.02 \\
\hline Bruininks, fine motor & 0.19 & $-0.41^{\star}$ & $-0.26^{\star}$ & -0.13 \\
\hline MFP (sensory) & 0.04 & 0.31 & -0.10 & $-0.31^{\star}$ \\
\hline FI (sensory) & 0.09 & -0.11 & $-0.35^{\star}$ & -0.10 \\
\hline LTS (sensory) & 0.11 & -0.14 & -0.05 & $-0.29^{\star}$ \\
\hline Conners & 0.08 & 0.07 & 0.17 & -0.03 \\
\hline Pollack & -0.12 & -0.25 & 0.07 & 0.04 \\
\hline
\end{tabular}

* A significant positive or negative $(-)$ correlation $(\mathrm{p}<0.05)$; † Pearson's correlation coefficient.

The differences between the groups were greater in the 5-6 year age group (Bruininks total score $105.2 \pm 30.5$ in index group vs 116.4 \pm 13.0 in controls; $p<0.05$ ), disappeared at $7-8$ years, and further increased at 9-12 years (151.7 \pm 15.0 vs $166.7 \pm 8.3$; $\mathrm{p}<0.05)$.

No differences between the index and control groups were observed in any of the three subtests of the Southern California Integration test (NFP, FI, and LTS) that were designed to reflect sensory-motor functioning. Children born to diabetic mothers had a significantly higher number of soft neurological signs in the Touwen and Prechtl examination (table 3).

There were 57 matched pairs in this comparison; in 33 pairs the scores were identical in the two groups. In 11 pairs the score was greater than 10 in the index children compared with the controls, and in three pairs the score of the control children was greater than in the index children. However, for these three control children the scores were 8 or less, lower than the score that is considered to be abnormal (10).

Applying the significance text to these mentioned results, we obtained a $\mathrm{z}$ statistic of -2.54 with a corresponding $\mathrm{p}$ value of 0.01 (two sided). As there are only 14 treatment-control pairs with non-identical values, the calculation of a $p$ value based on the $z$ statistics is only approximate.

The average score on the Pollack Tapper test was lower in the index group $(\mathrm{p}<0.001)$ (table $3)$. Across all ages the children in the index group had lower scores than the controls on the Pollack Tapper test, with a high variability between the children, resulting in a large SD. Further examination revealed an interaction with age: the greater difference in the average score was at $5-7$ years $(17.1 \pm 12.3$ in the index children vs $27.3 \pm 3.4$ in the controls; $\mathrm{p}=0.01$ ): The difference was smaller at $7-8$ years (23.9 \pm 11.6 vs $28.8 \pm 2.7 ; \mathrm{p}=0.02)$ and practically disappeared in the 9-12 year age group.

Table 3 reveals that children born to diabetic mothers obtained higher scores on the Conners abbreviated Parent-Teacher Questionnaire, indicating more hyperactivity signs, but the differences between the average scores were not significant (table 3 ).

Table 4 shows the correlation between the results of the neurodevelopmental assessments and the severity of diabetes, as indicated by glucose blood concentrations, urinary acetone, and per cent of glycosylated haemoglobin
$\left(\mathrm{HbA}_{1 \mathrm{c}}\right)$. A negative correlation was found between the per cent of $\mathrm{HbA}_{1 \mathrm{c}}$ and the scores on the Bender Gestalt test, as well as the total motor scores on the Bruininks test, indicating that the sensory-motor function of index group children tends to be lower with higher glycosylated haemoglobin concentrations. A similar negative correlation was found between positive urinary acetone and the motor ability of the children (table 4): the higher the acetonuria, the lower were the total motor scores on the Bruininks test.

There was a positive correlation between the glucose blood concentrations and the results of the Bender test and of the IQ on the WISC-R test. The correlation between maternal hyperglycaemia and maternal education was positive, indicating that maternal education may be the factor responsible for the high WISC-R and Bender-Gestalt scores.

No significant correlation was found between the medical status (hypoglycaemia, increased or decreased birthweight ) of the newborn infants and outcome of any of the associated variables in the index or control groups.

\section{Discussion}

Early school age children born to diabetic mothers had more soft neurological signs, and lower gross and fine motor achievements than pair matched control children born to nondiabetic mothers. Correlations were found between some variables that were related to the degree of maternal glycaemic control and some of the neurodevelopmental tests. We found no differences between the two groups of children in their IQ scores or in the physical growth, except for higher weight (percentiles) of the index children at examination. Differences between the groups on motor ability, hyperactivity, and attention span were smaller for the older index (9-12 years) children compared with the younger (5-6 years) children.

Other investigators have shown that children born to diabetic mothers develop normally, based on physical and neurological indices. ${ }^{16}{ }^{19-21} 36$ In this study we found that many indicators of sensory-motor development were lower in children born to diabetic mothers. A similar finding was described recently by Rizzo et $a l,{ }^{21}$ who evaluated psychomotor development, fine and gross motor function in children at ages 6 to 9 years, and found a significant negative correlation between maternal second and third trimester 
hydroxybutyrate concentration and performance on the Bruininks-Oseretzky test. ${ }^{21}$

The Touwen and Prechtl neurological examination showed a high incidence of soft neurological signs in the index group. This test is a good predictor of attention deficit and hyperactivity disorder (ADHD), ${ }^{25}$ implying, perhaps, that ADHD is more common among children of diabetic mothers. Moreover, mean scores on the Pollack tapper test were lower in the index group, also suggesting a higher prevalence of ADHD among the index children. Lambert and Sandoval ${ }^{37}$ found a high prevalence of pre and perinatal complications in children with $\mathrm{ADHD}$, including more health problems in their mothers, when compared with control (normal) children. Intellectual ability in children with ADHD is usually within the normal range, ${ }^{25}$ which agrees with the findings of our study. We found no differences in the IQ and Bender-Gestalt scores between children born to diabetic mothers and the control group.

Soft neurological signs may be signs of mild, non-specific brain damage. ${ }^{25} 38$ Variability in muscle tone (hypertonicity or hypotonicity) may cause delayed or abnormal motor development (Miyahara M, Department of Kinesiology, UCLA; unpublished observations). Index children may be able to compensate for slight motor impairment and their daily function may be normal. However, they may find complex motor tasks difficult.

Attention span and activity level were worse among index children at age 5-8 than at older ages. ADHD does seem to be more severe at early school age and tends to decrease in severity around puberty. ${ }^{24}$

Children born to diabetic mothers had higher percentiles for weight compared with control children. Overweight became more pronounced in the elder children (9-12 years), and at that age group there were four times more children with weights in the 90th percentile than in control children. Similar results were reported by Rizzo et $a l^{20}$ and by Metzger et al. ${ }^{36}$ Silverman et $a l^{39}$ found that the higher birthweight of infants born to diabetic mothers gradually disappears at 1-2 years of age. Overweight then reappears after the age of 5 years, and by 8 years of age, $50 \%$ of the children were at or above the 90th percentile. ${ }^{39}$

In conclusion, diabetes during pregnancy may affect the developing brain, inducing long term minor neurological impairment that is manifest as fine and gross motor functions, inattention, hyperactivity and soft neurological signs. The effects of maternal diabetes may result from the adverse effects of metabolic factors mainly during the second half of pregnancy that correlate with the degree of glycaemic control. These results emphasise the importance of good glycaemic control throughout pregnancy. The impaired neurobehavioural function is not related to the presence of major anomalies, implying that similar deficiencies may also exist in children born to mothers with gestational diabetes (where there is no increase in the prevalence of major anomalies). This was what we found. ${ }^{12}$
Supported by Grant No 032-4660 from the Israeli Ministry of Health. This study served as part of the requirements towards a $\mathrm{PhD}$ degree in the Hebrew University for N Ratzon.

1 Eskes TKAB, Mooij PNM, Steegers-Theunissen RPM, Lips JP, Pasker-de Jong PCM. Pregnancy care and prevention of birth defects. 7 Perinat Med 1992;20:253-65.

2 Goto MP, Goldman AS. Diabetic embryopathy. Curr Opin Ped 1994;6:486-91.

3 Hod M, Diamant YZ. The offspring of a diabetic mother-short and long range implications. Israel f Med Sci 1992;28:81-6.

4 Miller E, Hare JW, Cloherty JP, et al. Elevated maternal hemoglobin Alc in early pregnancy and major congenital
anomalies in infants of diabetic mothers. $N$ Engl $\mathcal{F}$ Med 1981;304: 1331-4.

5 Mills JL, Baker L, Goldman AS. Malformations of infants of diabetic mothers occur before the 7 th gestational week: Implications for treatment. Diabetes 1979;28:292-3.

6 Mills JL. Malformations in infants of diabetic mothers. Teratology 1982;25:285-394.

7 Mills JL, Knopp RH, Simpson JL, et al. NIHHD and diabetes in early pregnancy study: Lack of relation of increased malformation rates in infants of diabetic increased malformation rates in infants of diabetic mothers to glycemic con

8 Miodovnik M, Mimouni F, St John Dignan P. Major malformations in infants of IDDM women: Vasculopathy and early first-trimester poor glycemic control. Diabetes Care 1988; 11:713-18.

9 Blumenthal SA, Abdul-Karim W. Diagnosis, classifications, and metabolic management of diabetes in pregnancy: Therapeutic impact of self-monitoring of blood glucose and of newer methods of insulin delivery. Obstet Gynecol Surveys 1987;42:593-603.

10 Cordero L, London MB. Infants of the diabetic mother. Diabetes in Pregnancy 1993;20: 635-48.

11 Leslie RDG, Pyke DA, John PN, White JM. Hemoglobin Alc in diabetic pregnancy. Lancet 1978;ii:958-62.

12 Wolf A. Developmental evaluation on early school age children born to gestational diabetic mothers. [MSc thesis] Hebrew University, Jerusalem, Israel: 1997.

13 Ornoy A. Is the developing brain responsive to external stimulation? In: Tamir D, ed. Stimulation and intervention in infant development. Freund's Ltd. 1986: 316-18.

14 Schulte FJ, Michaelis R, Nolte R, et al. Brain and behavioral maturation in newborn infants of diabetic mothers. Neuropediatrics 1969;1:24-55.

15 Stehbens JA, Baker GL, Kitchell M. Outcome at age 1,3 and 5 years of children born to diabetic women. Am F Obstet Gynecol 1977;127:408-15.

16 Petersen BM, Pedersen SA, Greisen G, et al. Early growth delay in diabetic pregnancy: Relation to psychomotor delay in diabetic pregnancy: Relation to psy
development at age $4 . B M \mathcal{F} 1988 ; 296: 598-600$.

17 Sells CJ, Robinson NM, Brown Z, Knopp RH. Long-term developmental follow-up of infants of diabetic mothers. f Pediatr 1994;125:S9-17.

18 Cummins M, Norrish M. Follow-up of children of diabetic mothers. Arch Dis Child 1980; 55:259-64.

19 Persson B, Gentz J. Follow-up of children of insulindependent and gestational diabetes mothers. Acta Pediatrica Scandinavica 1984;73:349-58.

20 Rizzo TA, Metzger BE, Burns WJ, Burns K. Correlations between antepartum maternal metabolism and intelligence of offspring. N Engl f Med 1991;325:911-16.

21 Rizzo TA, Dooley SL, Metzger BE, Cho NH, Ogata ES, Silverman BC. Prenatal and perinatal influences on longterm psychomotor development in offspring of diabetic term psychomotor development in offspring o
mothers. Am f Obstet Gynecol 1995;173:1753-8.

22 Rizzo TA, Ogata ES, Dooley SL, et al. Perinatal complications and cognitive development in 2 to 5 year old children of diabetic mothers. Am f Obstet Gynecol 1994;171:70613.

23 Acardo PJ, Blondis TA, Whitman BY. Disorders of attention and activity level in a referral population. Pediatrics 1990;85:426-31.

24 American Psychiatric association. Diagnostic and statistical manual of mental disorders. 4 th edn. Washington, DC: American Psychiatric Association, 1994.

25 Ornoy A, Ariel L, Tennenbaum A. Inattention, hyperactivity and speech delay at 2-4 years of age as a predictor for and speech delay at 2-4 years of age as a predictor for 63.

26 Kark SL, Peritz E, Shiloh A, Slome C. Epidemiological analysis of the hemoglobin picture in parturient women of Jerusalem. Am f Public Health 1964;54:947-51.

27 Touwen BCL, Prechtl HFR. The neurological exemination of the child with minor nervous system dysfunction. Clin Developmental Med 1978;38.

28 Pollack M, Tuchler H. The Pollack tapper. An apparatus for the identification and differential diagnosis of reading in school children. The Head Teacher's Review. 1982.

29 Bender L. Instructions for the use of the Visual Motor Gestalt Test. New York: American Orthopsychiatric Association, 1964.

30 Koppitz ME. The Bender-Gestalt Test for young Children. Vol. II. NewYork: Grune \& Shatton, 1975.

31 Bruininks RH. Oseretsky Test of Motor Proficiency. Circle Pines, Minnesota: American Guidance Service, 1978. 
32 Ayres AJ. Sensory integration and the child. Los Angeles: Western Psychological Services, 1979.

33 Ayres AJ. Sensory Integration and the Praxis Test. Los Angeles: Western Psychological Services, 1989.

34 Conners CK. Rating scales for use in drug studies with children. Psychopharmacology Bulletin 1973;

35 Beyer BH. Handbook of tables for probability and statistics. 2nd edn. New York: The Chemical Rubber Co, 1968.

36 Metzger BE, Silverman B, Freinkel N. Amniotic fluid insulin concentration as a predictor of obesity. Arch Dis Child 1993;65:1050-2
37 Lambert NM, Sandoval J. The prevalence of learning disabilities in a sample of children considered hyperactive. f Abnormal Child Psychol 1980; 8:33.

38 Smith TR. Impaired motor skill (clumsiness) in otherwise normal children: A review. Child Care Health and Development 1992;18:283-99.

39 Silverman BL, Landsberg L, Metzger BE. Fetal hyperinsulinism in offspring of diabetic mothers: Association with the subsequent development of childhood obesity. Ann New York Acad Sci 1993;699:36-45.

.

$\sum_{0}^{\circ}$

ญे

$\overrightarrow{\hat{O}}$ 